\title{
Perspectiva histórica del encuentro de México con Asia-Pacífico: el caso de Filipinas
}

\section{\ntroducción} revisión de los principales acontecimientos que marcaron una nueva dinámica en las relaciones entre España y los territorios recién descubiertos de la Nueva España. Además, este ensayo se propone rescatar algunos elementos históricos que en gran aparte han sido de suma importancia en la conformación de los aspectos políticos, económicos y culturales de la amplia porción del mundo, que correspondió a los dominios de la Corona Española y no se les ha prodigado la atención que merecen para promover el conocimiento de nuestras raíces y fortalecer la identidad nacional.

Ahora bien, desde hace ya algunas décadas, el tener plena conciencia de la importancia del conocimiento de la historiografía del encuentro de México con los países de la zona Asia-Pacífico, y en especial de Filipinas, cobra particular relevancia al perfilarse, y más recientemente consolidarse, la Cuenca del Pacífico como uno de los fenómenos que seguramente marcarán el devenir en el tercer milenio.

\section{La expedición de López de Legazpi y Andrés de Urdaneta a las islas Filipinas}

Para algunos estudiosos del tema, se tienen evidencias culturales de la existencia de una relación prehispánica entre el continente americano y el asiático. A este respecto, Yoon Bong Seo hace una comparación interesante entre conceptos médicos, filosóficos, culturales y numerológicos, de donde extrae una serie de semejanzas que bien podrían corresponder a una

* Investigador del Departamento de Estudios del Pacífico de la Universidad de Guadalajara.

ORCID http://orcid.org/0000-0003-0344-6895 interrelación entre el continente americano y el asiático aún antes del descubrimiento del primero de éstos. ${ }^{1}$ Sin embargo, no existen documentos o pruebas irrefutables de que hasta antes de la conquista de la Nueva España se haya establecido un contacto constante entre ambos continentes.

De esta manera, el primer contacto suficientemente documentado entre México y el Oriente se registró en 1565, cuando se inició la exploración y conquista de las islas Filipinas, las cuales habían sido bautizadas con ese nombre por Ruy López Villalobos en honor al rey Felipe II de España. El mérito de haber encabezado esa aventura al Oriente corresponde a Miguel López de Legazpi y Andrés de Urdaneta quienes, habiendo zarpado del puerto de La Navidad el 21 de noviembre de 1564, avistaron la isla de Samar el 13 de febrero de 1565. Así, decía don Carlos Pizano y Saucedo, el 19 de noviembre de 1994, "en el puerto de La Navidad [...] se inició hace 430 años el encuentro entre América y Asia”. ${ }^{2}$

Pero, si bien el viaje de exploración y la conquista de los nuevos territorios de las islas mencionadas marcó el inicio de la aventura asiática, la gloria del viaje de retorno corresponde a Andrés de Urdaneta porque él fue quien descifró el enigma del tornaviaje en el Pacífico, lo que muchos otros no habían podido lograr. De modo que "volver a la Nueva España fue hazaña exclusiva de Urdaneta. El tornaviaje es palabra evocadora, concepto surgido de lo que habría de ser la historia del Pacífico, pues las relaciones entre América y Asia habrían de ser ya, por siempre, recíprocas y cada vez más importantes, crecientes y trascendentes". 3

Este viaje de retorno fue planeado una vez que, no sin grandes dificultades, se estableció López de Legazpi en la isla de Cebú, por lo que 
el 1 de junio de 1565 uno de los galeones, al mando de Urdaneta, partió de regreso a América y el 1 de octubre de ese mismo año llegó al puerto de La Navidad, “así, el eslabón de galeones entre Filipinas y la Nueva España quedó definitivamente establecido. Desde entonces, las naos comenzaron a hacer viajes regulares entre los dos puntos, llevando hombres, materiales y plata de Nueva España, y trayendo porcelana, oro y seda de Filipinas". ${ }^{4}$ Esto dio como resultado que se inaugurara una etapa de negocios lucrativos entre ambos márgenes del Pacífico, cuyos lazos visibles eran Manila en Filipinas y Acapulco en México. De esta manera, se empezó a notar que "al iniciarse la relación con el poniente en el siglo XVI, aumentaron en México las influencias asiáticas de manera directa". ${ }^{5}$

\section{Relaciones políticas y comerciales entre México, Asia-Pacífico y Filipinas}

Miguel López de Legazpi fue el primer gobernador de las Filipinas y, aunque español de nacimiento, pasó 35 años en Manila, ciudad fundada por su nieto Juan de Salcedo, nacido en Toluca e hijo de criollos, a quien se le conoce por su trayectoria de pacificador y fundador de ciudades. Este hecho es trascendente puesto que fue un novohispano, Juan de Salcedo, en el que recayó la responsabilidad de la pacificación de Filipinas y al final de cuentas se le reconoce como un héroe en la crónica de Antonio de Marga, Sucesos de las islas Filipinas (cuya primera edición apareció en México, en 1609). En esta crónica se asegura que "este héroe, llamado Hernán Cortés de las Filipinas, fue en verdad el brazo inteligente de Legazpi. Por su prudencia, por sus grandes cualidades, por su talento y valor personal se captó las simpatías de los filipinos y se sometieron éstos a sus enemigos". ${ }^{6}$
En este sentido, también es conveniente rescatar lo referente a la participación novohispana, ya que la ejecución de todo lo relativo a la exploración, conquista y pacificación, prácticamente es una obra que se puede atribuir a una generación de novohispanos que se involucraron en la aventura hacia el Pacífico Asiático. En esto estriba la razón de por qué "a través de los años se fue consolidando nuestra influencia étnica, lingüística, cultural, religiosa y costumbrista". ${ }^{7}$ Todo esto le imprimió un sello característico criollo al lance de la Nueva España en su afán de secundar a la madre patria en sus empresas.

Ahora bien, la relación comercial que se estableció entre Filipinas y México durante la etapa colonial posibilitó un acercamiento en muchos otros aspectos y estrechó los lazos que se establecen entre los pueblos. Así, además de las condiciones políticas prevalecientes, las cuales sujetaron a las Filipinas a la capital de la Nueva España, desde el punto de vista comercial la sujeción se tornó muy fuerte debido a los intereses que se suscitaron con el intercambio de las mercaderías, legales e ilegales, que por esa vía se realizaron. De esta manera, "las relaciones sociales, mercantiles y diplomáticas de las islas conquistadas por Legazpi fueron reguladas y vigiladas desde la ciudad de México. El vínculo fue tan estrecho que hay autores que destacan que las Filipinas estuvieron más estrechamente ligadas con esta capital, que las mismas provincias internas del virreinato". 8

De este modo, no obstante que sobre la actividad comercial que se desarrollaba desde la ciudad de México pesaban restricciones impuestas desde España, el comercio floreciente que se estaba llevando a cabo con Asia por la ruta del Pacífico benefició primordialmente a los empresarios establecidos en la ciudad mencionada. Asimismo, el poder del que gozaban 
estos empresarios siempre estuvo presente en las decisiones que llevaron a establecer a Acapulco como puerto designado oficial para el intercambio comercial por esa vía. Esto, además del control que les permitía, redujo sustancialmente los gastos de transporte que de otra manera se habrían hecho si el desembarco de las mercancías se hubiera realizado en otros puertos más alejados del área de la ciudad de México.

Sin embargo, a finales del siglo XVI, debido al auge que registró el comercio entre ambas márgenes del Pacífico y al efecto contraproducente que esto ocasionaba en los intereses de los comerciantes radicados en Sevilla, las restricciones se tornaron más rígidas y hacia el siglo XVIII "los Borbones ejercieron un mayor control con el propósito de disminuir el tráfico mercantil de los novohispanos con Asia y evitar la fuga de capitales". ${ }^{9}$ No obstante esta mayor regulación, existen evidencias de que las naos en su travesía transoceánica hacían escalas técnicas en las que descargaban toda clase de mercancías. Así, el galeón que salía sobrecargado de Manila llegaba con muchas toneladas menos a Acapulco, lo que dejaba fuera del control de las autoridades una gran parte de las mercancías transportadas por esta vía, además de que podrían ser clandestinas las mercancías objeto de este manejo.

Por otra parte, este intercambio comercial posibilitó la puesta en operación de algunos fondeaderos a lo largo del litoral que recorrían las naos desde California hasta Acapulco, los cuales ejercieron una función complementaria muy importante, puesto que servían de fuente de provisiones para realizar reparaciones a las naves en caso de emergencia y para protegerse de la piratería, razón por la que se establecieron guarniciones en algunos de estos puertos de mediana importancia.

Finalmente, todo este rico intercambio comercial que llevaba aparejados aspectos culturales, sociales y hasta naturales, vino a menos con la clausura de los viajes de la nao, decretada por medio de la cédula del 14 de septiembre de 1813, lo que además provocó que una gran parte de los puertos secundarios de la franja mexicana del Pacífico resintieran los efectos y a partir de entonces empezaran a registrar un estancamiento, el cual se vio todavía más acendrado con el inicio de la etapa independiente y el hecho de que las nuevas administraciones dieran la espalda al mar y se encerraran en los límites más estrechos del país. $^{10}$

\section{La herencia hispana en Asia-Pacífico y Filipinas y la mezcla de culturas}

Aunque no se pueda hablar precisamente de un proceso de transculturación ${ }^{11}$ entre América y Asia, sí se podrían considerar algunos aspectos de las culturas de Asia-Pacífico que muestran ciertos rasgos hispanos y viceversa. Así, no obstante que el procedimiento para la evangelización se modificó durante su aplicación en las islas Filipinas, puesto que por experiencia se optó por aprender las lenguas nativas en lugar de imponer el aprendizaje del español, ${ }^{12}$ este idioma tuvo una difusión a través de múltiples mecanismos, de manera que hasta la fecha existen pueblos que tienen una gran influencia en su lengua nativa, a pesar de que la imposición del idioma inglés, como es el caso en Filipinas, ha tenido un impacto definitivo desfavorable en el uso del idioma español.

Pero no es tan sólo en el uso del idioma, sino también en el gusto por las letras, en donde se puede notar cierta presencia hispana en Filipinas y la región de Asia-Pacífico. Esta evidencia se puede constatar en la existencia, cada vez en mayor número, de instituciones que se dedican formalmente a la enseñanza del español tanto en Filipinas como en Japón, Corea y China, por hablar sólo de las más importantes en el área. Además, el número de obras traducidas del español a los idiomas que se hablan en la zona, es un buen indicador de que el gusto por el idioma sigue vigente, no obstante el paso de los años. ${ }^{13}$

Por otra parte, también es notoria una mezcla de costumbres tanto en el otro lado del océano, sobre todo en Filipinas y su área de influencia, y en nuestro país, ya que la ruta 
comercial que se estableció a través del Pacífico también dio pie a una migración de orientales hacia este lado del océano. Esto se puede apreciar, por ejemplo, en la costumbre de las peleas de gallos, la que hoy se considera como muy mexicana, la tradición de la china poblana, el uso de chales y mantones, cuyo origen es asiático, y así una serie de inimaginables coincidencias en los usos y costumbres de los pueblos de México y de Filipinas y la zona de Asia-Pacífico.

Finalmente, en el aspecto culinario también se puede observar una combinación tanto en el uso de ingredientes de ambos lados del océano, como de guisos que son tradicionales en ambas regiones. Además, es notoria la existencia de árboles frutales similares tanto en aquella región como en México, propiciada también por la similitud de condiciones climatológicas, lo que es una clara muestra de un intercambio en este aspecto.

\section{Conclusiones}

La perspectiva que nos proporciona el acercamiento histórico a la relación que desde la época colonial se experimentó entre América y Asia-Pacífico, y en el caso que nos ocupa entre México y Filipinas, es sumamente interesante, puesto que nos ayuda a evaluar las posibilidades presentes y futuras de los intercambios, de la índole que éstos sean, entre las entidades mencionadas.

También es importante reconocer que, más allá de las aparentes diferencias culturales, hay un gran número de coincidencias en este sentido que pudieran fortalecerse dedicando tiempo al estudio y acercamiento con esa parte del mundo, la cual, como se vio en el presente trabajo, no nos es totalmente extraña, o por lo menos no debería serlo tanto.

Así, el enfrentamiento de los retos y desafíos que nos plantea el nuevo milenio, con las tendencias aparentemente opuestas de los fenómenos de la globalización y regionalización, en lo que toca a una relación renovada, no partirá de cero sino de un pasado, si bien no común, sí por lo menos en estrecho contacto, cimentado en múltiples factores culturales, étnicos y sociales, lo que facilitaría en un momento dado el restablecimiento de mejores relaciones entre México y Asia-Pacífico, especialmente con Filipinas.

\section{Notas}

1 Yoon Bong Seo, "Encuentro de dos mundos: México y Poniente. El fenómeno de la transculturación", en III Coloquio La cuenca hispana del Pacífico. Pasado y futuro, 19 y 20 de noviembre de 1994, Jaime Olveda (coord.), Sociedad de Geografía y Estadística del Estado de Jalisco, s. a., s. e., s. f., s. 1., pp. 81-95. También, del mismo autor, "Culturas náhuatl y oriental: coincidencias numerológicas", en Jalisco hoy, 11 de octubre de 1993, núm. 32, pp. 62-65.

2 Carlos Pizano y Saucedo, "El puerto de La Navidad y la expedición de López de Legazpi y Urdaneta a las islas Filipinas", en op. cit., Jaime Olveda (coord.), p. 43.

3 Ibid., pp. 44-45.

4 Ibid., pp. 50-51.

5 Yoon Bong Seo, "Encuentro de dos mundos: México y Poniente. El fenómeno...", en op. cit., Jaime Olveda (coord.), p. 84.

6 Antonio de Marga apud Carlos Pizano y Saucedo, art. cit., p. 55.

7 J. Jesús González Gortázar, "La gesta de México en el Pacífico", en op. cit., Jaime Olveda (coord.), p. 150.

8 Jaime Olveda, "La Navidad. El comercio y la penetración filipina", en Los puertos noroccidentales de México y su papel en la comunicación de México con los países de Asia Pacífico, Jaime Olveda y Juan Carlos Reyes (coords.), El Colegio de Jalisco-Universidad de Colima-INAH, México, 1994, p. 23.

9 Ibid., p. 25.

10 Jaime Olveda, "El puerto de La Navidad. Perlas, comercio y filipinos", en op. cit., Jaime Olveda (coord.), pp. 79-80.

11 Para una definición precisa del término "transculturación”, ver Yoon Bong Seo, "Encuentro de dos mundos: México y Poniente. El fenómeno...”, en op. cit., Jaime Olveda (coord.), pp. 87-88.

12 Claudia Macías, "Aproximaciones lingüístico-literarias a una relación filipina del siglo XVII", en op. cit., Jaime Olveda (coord.), pp. 117-136.

13 Fernando Torres de la Torre, "Presencia cultural hispana en la Cuenca del Pacífico", en op. cit., Jaime Olveda (coord.), pp. 97-116. 